\title{
Patient satisfaction with treatment for alcohol use disorders: comparing patients with and without severe mental health symptoms
}

This article was published in the following Dove Press journal:

Patient Preference and Adherence

4 August 2016

Number of times this article has been viewed

\author{
Stacey L McCallum' \\ Jane $M$ Andrews ${ }^{2,3}$ \\ Matthew D Gaughwin ${ }^{3,4}$ \\ Deborah A Turnbull' \\ Antonina A Mikocka-Walus ${ }^{5}$ \\ 'School of Psychology, Faculty \\ of Health Sciences, University \\ of Adelaide, ${ }^{2}$ Department of \\ Gastroenterology and Hepatology, \\ Royal Adelaide Hospital, ${ }^{3}$ School of \\ Public Health, University of Adelaide, \\ ${ }^{4}$ Drug and Alcohol Consultation \\ Liaison Service, Royal Adelaide \\ Hospital, Adelaide, SA, Australia; \\ ${ }^{5}$ Department of Health Sciences, \\ University of York, Heslington, UK
}

Background: Previous studies suggest patients with co-occurring alcohol use disorders (AUDs) and severe mental health symptoms (SMHS) are less satisfied with standard AUD treatment when compared to patients with an AUD alone. This study compared patient satisfaction with standard AUD treatment among patients with and without SMHS and explored how standard treatment might be improved to better address the needs of these patients.

Methods: Eighty-nine patients receiving treatment for an AUD either at an inpatient hospital, outpatient clinic, inpatient detoxification, or residential/therapeutic community services were surveyed. Patient satisfaction with treatment was assessed using the Treatment Perception Questionnaire (range: 0-40). Patients were stratified according to their score on the Depression Anxiety Stress Scale. Forty patients scored in the extremely severe range of depression (score $>14$ ) and/ or anxiety (score $>10$ ) (indicating SMHS) and 49 patients did not. An inductive content analysis was also conducted on qualitative data relating to areas of service improvement.

Results: Patients with SMHS were found to be equally satisfied with treatment (mean $=25.10$, standard deviation $=8.12$ ) as patients with an AUD alone ( mean $=25.43$, standard deviation $=6.91$ ). Analysis revealed that being an inpatient in hospital was associated with reduced treatment satisfaction. Patients with SMHS were found to be significantly less satisfied with staffs' understanding of the type of help they wanted in treatment, when compared to patients with AUDs alone. Five areas for service improvement were identified, including staff qualities, informed care, treatment access and continuity, issues relating to inpatient stay, and addressing patients' mental health needs.

Conclusion: While findings suggest that AUD treatment services adequately meet the needs of patients with SMHS in treatment, patients with SMHS do feel that staff lack understanding of their treatment needs. Findings have important implications as to how current health care practice might be improved according to the patient's perspective of care.

Keywords: $\mathrm{MeSH}$, alcohol use disorder, treatment, mental disorder, comorbidity, patient satisfaction

\section{Introduction}

Patient compliance and dropout are considered significant challenges in the treatment of addiction. Previous studies report that only $28 \%$ of persons with addictions seek treatment in a given year, ${ }^{1}$ and of those, the proportion of patients who drop out of treatment ranges from $36 \%$ and $44 \%$ across addiction services. ${ }^{2}$ Patient satisfaction with treatment refers to the degree to which patients perceive the treatment service and staff have addressed their individual wants and needs. ${ }^{3}$ Patient satisfaction with treatment is recognized as a particularly important construct in the treatment of addictions, ${ }^{4}$ due to its close link to patient adherence and compliance. Researchers propose that
Correspondence: Stacey L McCallum Room 715, Hughes Building, School of Psychology, Faculty of Health Sciences, University of Adelaide, North Terrace, Adelaide, SA 5005, Australia

Tel +61883135693

Fax +61883133770

Email s.mccallum@adelaide.edu.au (c) (i) (5) 2016 Mccallum et al. This work is published and licensed by Dove Medical Press Limited. The full terms of this license are available at https://www.dovepress.com/terms.php (c) hereby accept the Terms. Non-commercial uses of the work are permitted without any further permission from Dove Medical Press Limited, provided the work is properly attributed. For permission for commercial use of this work, please see paragraphs 4.2 and 5 of our Terms (https://www.dovepress.com/terms.php). 
patients who are satisfied with treatment are more likely to continue treatment, enabling treatment to be more effective. ${ }^{5}$ Patient satisfaction has been linked to positive outcomes of addiction treatment, including longer retention in inpatient services, ${ }^{6}$ increased variation of services utilized in outpatient settings, ${ }^{7}$ increased use of aftercare programs, ${ }^{8,9}$ and reduced alcohol intake. ${ }^{5}$

Among patients who seek treatment for an alcohol use disorder (AUD), 33\%-55\% present with additional depression and/or anxiety symptoms that require clinical intervention. ${ }^{10,11}$ Patients with co-occurring severe mental health symptoms (SMHS) are a particularly vulnerable group in standard AUD treatment. ${ }^{12}$ Compared to patients with a single AUD, patients with SMHS are less likely to engage, retain, and respond to treatment. ${ }^{13,14}$ Accordingly, patients with SMHS are at risk of poorer treatment outcomes such as increased risk of disability, ${ }^{15}$ suicidality, ${ }^{16}$ psychopathology, and overall poorer quality of life. Furthermore, patients with SMHS strain treatment services through high service utilization and costs. ${ }^{17,18}$

In standard AUD treatment, a proportion of patients present with symptoms of depression and/or anxiety, which fall short of meeting full diagnostic criteria; ${ }^{12}$ but nonetheless negatively affect the patient's functioning and treatment outcomes. ${ }^{19}$ Researchers have argued that diagnostic assessments lack sensitivity and rather recommend the use of measures of mental health symptoms. ${ }^{20}$ While a proportion of patients will experience a decline in symptoms of anxiety and depression after detoxification without clinical intervention, a proportion will continue to experience symptoms posttreatment, placing them at an increased risk of relapse. ${ }^{21}$

Patients with SMHS present to treatment with complex needs ${ }^{12}$ that are often not fully addressed by standard AUD treatment. ${ }^{14,22}$ As a result, there is a common understanding in the literature that patients with SMHS report poorer satisfaction with standard AUD treatment when compared to patients with a single AUD. ${ }^{4}$ We have identified, however, only two studies that directly compared patient satisfaction among those with co-occurring mood disorders and AUDs to patients with a single AUD, within an addiction treatment setting. ${ }^{11,14}$ A 2009 prospective study $(n=2,496)$ found that patients with both mood disorders and AUDs were significantly less satisfied with treatment, compared to patients with a single AUD. ${ }^{14}$ However, a prospective study $(n=71)$ reported no differences between groups in the same setting. ${ }^{11}$ Another prospective study $(n=92)$ reported no significant differences in satisfaction among patients with and without co-occurring diagnoses, in a psychiatric setting. ${ }^{22}$ It should be noted that these studies identified involved samples where patients met diagnostic criteria for both disorders, possibly limiting their interpretability in relation to patients with SMHS. A 2011 systematic review of 27 studies investigated patient satisfaction with treatment among patients with cooccurring mental disorders and substance use diagnoses. The authors reported that studies have yet to control potential confounding variables that have been linked to patient satisfaction for single diagnoses samples, ${ }^{4}$ including treatment setting $^{23}$ and patient treatment readiness. ${ }^{4}$

A previous study suggests that patients with an external locus of health control toward the course of their AUD are less motivated for treatment ${ }^{24}$ and consequently may be less satisfied. At the same time, those patients with an internal locus of control more readily accept and participate in treatment. ${ }^{25}$ Patient appraisals of treatment are formed based on cognitive judgmental processes. ${ }^{26}$ It is, therefore, important to consider patients' general cognitive judgments to ensure that their appraisals of treatment are a true reflection of their actual treatment experiences. Research has yet to consider the role of these variables in the assessment of patient satisfaction with treatment.

This study aimed to compare patient satisfaction with standard AUD treatment among patients with and without SMHS. Patient satisfaction with treatment was assessed according to the Treatment Perception Questionnaire (TPQ), which assesses patients' perceptions of both the treatment service/program and staff. On the basis of previous research, we hypothesized that patients with SMHS would be less satisfied with standard treatment when compared to patients with a single AUD. This study was designed to control for the potential impact of treatment setting, treatment readiness, locus of health control, and life satisfaction, on patient satisfaction with treatment. We hypothesized that, collectively, these variables would play a large role in patients' assessments of treatment. A secondary aim of this study was to investigate whether patients with SMHS are less satisfied with certain aspects of treatment when compared to AUD patients without SMHS, and how areas of treatment might be improved from the patient perspective. To the authors' knowledge, this is the first study to compare patient satisfaction with AUD treatment among patients with and without SMHS, while controlling for the impact of previously underresearched variables.

\section{Methods \\ Design}

This study used a cross-sectional design to compare patient satisfaction with standard AUD treatment among patients 
with and without SMHS. Both quantitative and qualitative data were obtained from patients using a survey methodological approach.

\section{Setting}

Patients were recruited from four services that operate under the same government-funded body in Adelaide, South Australia. These services offer standard AUD treatment, including both pharmacological and/or psychological approaches specifically tailored toward reducing patients' alcohol use. Services included an inpatient tertiary hospital service where patients received pharmacological treatment, assessments, and coordination of care for injuries or diseases related to alcohol (inpatient hospitalization). An outpatient service that operates within the same tertiary hospital was also included (outpatient). This service provides pharmacological treatment and general counseling support to patients and acts as a follow-up to inpatient stay. This study also recruited patients from an inpatient withdrawal management unit located within a specialist psychiatric hospital where substance withdrawal is monitored by medical staff (inpatient detoxification). At this service, patients' withdrawal from alcohol is monitored for 5-7 days with medical, and pharmacological interventions (eg, benzodiazepines). Comprehensive assessments, discharge planning, and counseling are also offered. The final service was a residential therapeutic community where patients reside for a period of 3-12 months and receive counseling from staff and peers and engage in a structured program.

\section{Sample}

Participants were required to meet Diagnostic and Statistical Manual criteria for an AUD, and alcohol had to be their main substance of concern. Participants were excluded if they did not attend their outpatient appointment, had consumed alcohol in the 5 days prior to intake to the study, or were under the age of 18 years. Patients were required to be abstinent from alcohol for at least 5 days to minimize the impact of alcohol withdrawal syndrome on patients' reported anxiety symptoms. Participants were excluded if they were not cognitively able to participate or if treatment staff assessed the participant as too medically or psychologically unwell to participate.

\section{Procedure}

Ethical approval was obtained from Royal Adelaide Hospital Human Research Ethics Committee and University of Adelaide Human Research Ethics Committee. All procedures were conducted in accordance with the National Health and Medical Research Council ethical guidelines. Written informed consent was obtained from all participants prior to inclusion in the research study. Participant recruitment occurred at the tertiary hospital between September 2013 and June 2014. Participants were recruited at the residential/ therapeutic community from November 2013 to February 2014, and at the inpatient withdrawal unit from February 2014 to April 2014. The primary investigator consulted with treatment staff to identify patients who might be eligible for the study (eg, alcohol main substance of concern, meet AUD criteria; $n=170$ ) (Figure 1). A total of 143 patients were visited, and the staff then conducted a prescreen to assess

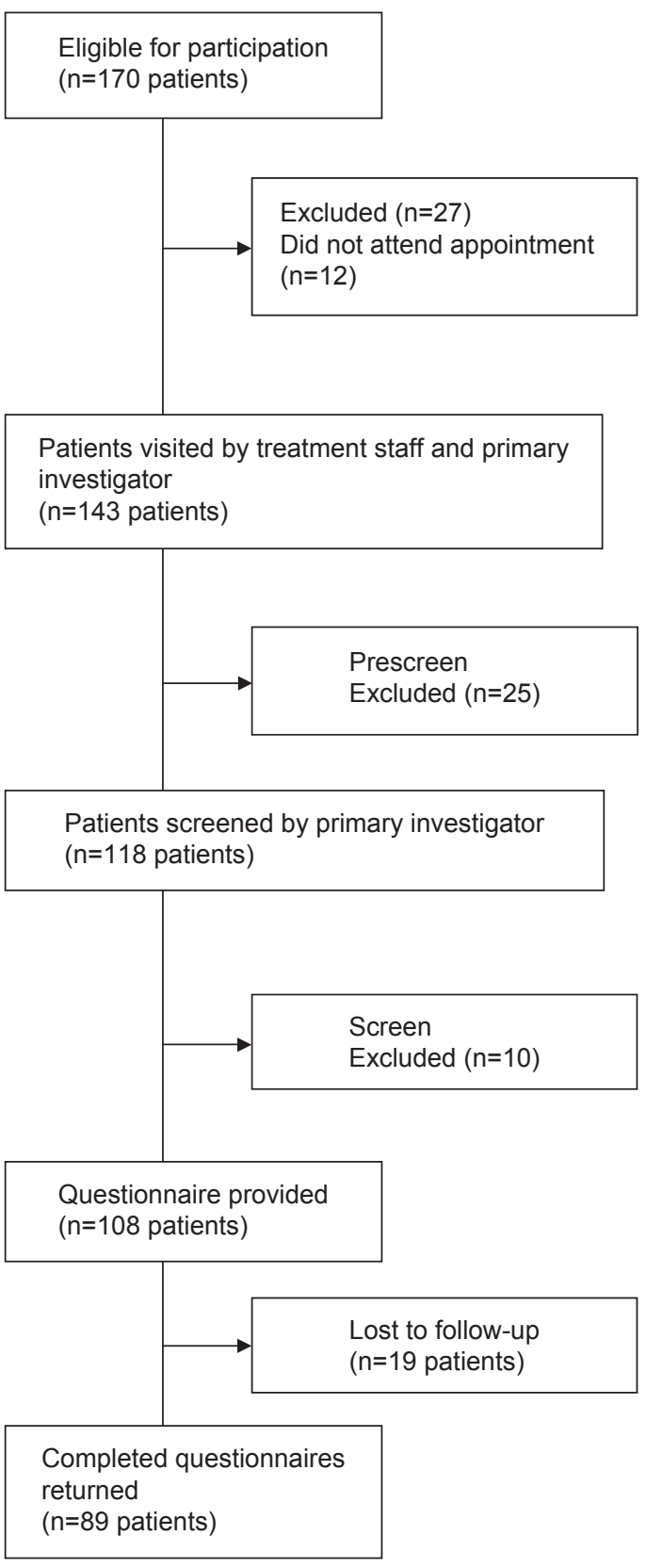

Figure I Process of recruitment. 
if the participant was well enough to participate. A total of 118 patients were invited to participate and were screened to assess AUD criteria and cognitive ability; ten participants were excluded for cognitive impairment. The questionnaire was given to 108 patients and was returned to the primary investigator. However, in some cases, participants wished to complete the questionnaire at a later time, and thus 19 surveys were lost to follow-up. A total of 89 respondents returned completed surveys.

\section{Measures}

\section{Screening}

AUD diagnoses were assessed according to the Mini International Neuropsychiatric Interview (MINI 6.0) ${ }^{27}$ for 12-month AUD Diagnostic and Statistical Manual of Mental Disorders, fourth edition (DSM-IV) criteria, as instruments for DSM-5 criteria were not available at the time of study design. An additional question was added to the screening instrument to incorporate the added craving criterion in the DSM-5. ${ }^{28}$ Patient cognitive functioning was assessed using the MINI Mental State Examination. ${ }^{29}$

\section{Questionnaire}

Patients provided demographic information and clinical characteristics using the Addiction Severity Index-Self Report (ASI-SR). ${ }^{30,31}$ The ASI-SR assesses seven areas of functioning affected by addiction: employment, medical, psychiatric, familial/social, alcohol, drug, and legal. A composite score for each area is produced (0-1), where higher scores represent more severe problems with functioning. ${ }^{32}$ Internal consistency of the ASI ranges from moderate to high (0.70 and higher). ${ }^{33}$

\section{Patient satisfaction with treatment (outcome variable)}

Patient satisfaction with treatment was assessed using the TPQ. ${ }^{3}$ The TPQ includes ten Likert scale items; five items are negatively worded to reduce acquiescence bias. The TPQ was developed in inpatient and community treatment samples for substance use disorders and methadone maintenance programs; ${ }^{3}$ it was chosen due to its validity, brevity, and ability to be applied in a variety of modalities of addiction treatment; ${ }^{3}$ and participants are required to respond to ten items using a 5-point Likert scale, ranging from strongly disagree to strongly agree. The sum of all ten items is calculated to produce a global satisfaction score, ranging from 0 to 40 . Higher scores represent increased satisfaction with treatment, while lower scores represent dissatisfaction with treatment.
Assessments of internal consistency have revealed goodto-excellent correlations for the staff perception (0.58-0.86) and average-to-excellent correlations for program perception subscales (0.37-0.92). ${ }^{3}$ The TPQ also includes an openended item where patients provide qualitative feedback and make recommendations for improvements to treatment. ${ }^{3}$ The item is:

Please write down in the box below any comments you would like to give us about the treatment you have received here. We would be very interested if you could tell us how you think we could improve the service.

The qualitative analysis of the open-ended TPQ response was added to the overall quantitative analysis using complimentary techniques. ${ }^{34}$ This process is where different data sources offer complementary information on the one issue, which can be combined to examine different aspects of a research question. ${ }^{34}$

\section{Confounding variables}

Treatment readiness was assessed using the Readiness to Change Questionnaire-Treatment Version (RTCQ-TV). ${ }^{35,36}$ The RTCQ-TV assessed participants' stage of thinking toward changing their AUD course, according to the stage of change theory. ${ }^{37}$ Assessments of internal consistency indicate a moderate correlation for the precontemplation scale (0.34-0.51), adequate correlation for the contemplation scale (0.30-0.40), and good correlation for the action scale $(0.32-0.67) .{ }^{35}$ Locus of health control was assessed using the Multidimensional Health Locus of Control (MHLC) ${ }^{38,39}$ questionnaire (Form C). Participant responses were allocated to two subscales: internal or external. Assessments of internal consistency indicate good correlations for internal (0.85-0.87), chance (0.79-0.82), doctors $(0.71)$, and other people $(0.70-0.71)$ subscales. ${ }^{40}$ Life satisfaction was assessed using the Satisfaction with Life Scale (SWLS), ${ }^{26}$ which produced an overall satisfaction score, ranging from 5 to 35 . The SWLS is considered a highly validated and reliable measure of satisfaction, which can be applied in a wide range of groups and samples. ${ }^{41}$

\section{Patient mental health symptoms (predictor variable)}

Patient mental health symptoms were assessed using the Depression Anxiety Stress Scale (DASS-21) (range: 0-21). ${ }^{42}$ Respondents were asked how much items applied to them within the previous 7 days. However, if participants had undergone alcohol withdrawal in the 7 days prior, they were asked to respond according to how they felt since withdrawal symptoms have subsided. Participants who scored in the 
"extremely severe" range of the depression (DASS-21 score of 14 and above) and/or anxiety (DASS-21 score of 10 and above) subscales were grouped as patients with SMHS. This cutoff was used as symptoms within this range are considered clinically significant and require intervention and treatment. ${ }^{42}$ Patients scoring in remaining categories were allocated to the "single AUD group". Measures of internal consistency for the DASS-21 in a clinical population have reported goodto-excellent coefficients for the depression (0.96), anxiety (0.89), and stress $(0.93)$ subscales. ${ }^{43}$

\section{Data analysis}

Power analysis indicated that 80 cases $(n=40$ with and $n=40$ without SMHS) were required to conduct univariate comparisons between the groups, based on a mean difference of 5 points on the TPQ and at the $5 \% \alpha$ level with a power of $87 \%$. Multiple regression analysis was based on a requirement of ten cases per predictor. ${ }^{44}$ The sample of 80 patients was considered adequate to account for the five predictors intended to enter the analysis. It was anticipated that data may be missing in $10 \%$ of cases; therefore, the total number of completed surveys required for this study was increased to 88. Patient recruitment ceased after the author had obtained at least 88 completed surveys.

Independent samples $t$-tests and chi-square $\left(\chi^{2}\right)$ analyses were conducted to compare groups on the variables of interest. A hierarchical multiple regression was conducted to determine if patient mental symptoms predicted a significant amount of variance in patient satisfaction, when controlling for the impact of confounding variables. Multicollinearity between the variables "outpatient" and "inpatient hospitalization" was identified; accordingly, two models were created in the regression analysis. All categorical predictor variables were dummy coded, and treatment setting (Model 1: inpatient hospitalization, outpatient, and residential therapeutic community; Model 2: inpatient hospitalization, outpatient, and inpatient detoxification), treatment readiness $(0=$ contemplation, $1=$ action), locus of health control $(0=$ internal, $1=$ external $)$, and life satisfaction were entered into the model at Step 1. Patient mental symptoms were entered at Step 2.

This study also aimed to determine if patients with SMHS were significantly more dissatisfied with specific aspects of treatment, when compared to patients without SMHS. To test this question, all items of the TPQ satisfaction instrument were recoded into new variables. Responses of 0 "strongly disagree" were recoded as 1 and all remaining responses were recoded as 0 . We chose to focus only on "strongly disagree" responses to detect areas of positive dissatisfaction and thus identify aspects that may benefit from review. $\chi^{2}$ tests for independence (with Fisher's exact test) were conducted for each item of the TPQ. In the presentation of results, negatively worded items were reworded to maintain consistency.

An inductive content analysis was conducted on qualitative data produced from the open-ended question of the TPQ on service improvement. The basic inductive content analysis approach aims to reduce qualitative text into related codes and themes ${ }^{45}$ and is commonly used to reduce text from open-ended survey questions. ${ }^{46}$ The inductive content analysis approach involved three main stages: open coding, grouping the data, and abstraction. ${ }^{47}$ Codes were generated by rereading the text and allocating appropriate headings, codes, and themes to the data. Codes were grouped according to positive comments/satisfaction or negative comments/ dissatisfaction, and subsequently coded as to whether data related to treatment staff or the treatment service. The final stage involved abstraction of the data, where main categories were formulated based on the grouping of headings of codes according to similarities and shared ideas. ${ }^{47}$

\section{Results \\ Demographic, clinical, and treatment- related characteristics}

A total of 89 completed surveys were included in analysis (response rate of $82 \%$ ). The sample comprised $67 \%$ men and $33 \%$ women, with a mean age of 48.32 years (Table 1 ). Patients with SMHS reported significantly higher symptoms of depression ( $\mathrm{M}=14.13, \mathrm{SD}=4.40 \mathrm{vs} \mathrm{M}=5.55, \mathrm{SD}=4.03)$, anxiety $(\mathrm{M}=13.10, \mathrm{SD}=4.18$ vs $\mathrm{M}=3.04, \mathrm{SD}=2.80)$, stress $(\mathrm{M}=14.45, \mathrm{SD}=3.76$ vs $\mathrm{M}=5.59, \mathrm{SD}=3.55)$, and overall higher psychiatric severity $(\mathrm{M}=0.51, \mathrm{SD}=0.21$ vs $\mathrm{M}=0.31, \mathrm{SD}=0.21$ ) compared to patients with single AUDs. Patients with SMHS also reported more significant difficulties in areas of medical $(\mathrm{M}=0.49, \mathrm{SD}=0.38$ vs $\mathrm{M}=0.33$, $\mathrm{SD}=0.34)$, familial $/$ social $(\mathrm{M}=0.40, \mathrm{SD}=0.23 \mathrm{vs} \mathrm{M}=0.28$, $\mathrm{SD}=0.27)$, and alcohol severity $(\mathrm{M}=0.62, \mathrm{SD}=0.32$ vs $\mathrm{M}=0.47$, SD $=0.29$ ). Patients with SMHS were significantly less satisfied with life compared to patients with single AUD $(\mathrm{M}=12.97, \mathrm{SD}=6.85$ vs $\mathrm{M}=16.82, \mathrm{SD}=8.20)$. No differences were observed between groups on treatment readiness, locus of health control, and satisfaction with treatment $(\mathrm{M}=25.10$, $\mathrm{SD}=8.12$ vs $\mathrm{M}=25.43, \mathrm{SD}=6.91$ ).

\section{Impact of SMHS on patient satisfaction with treatment}

Table 2 lists the impact of patient mental symptoms on satisfaction with treatment while accounting for confounding 


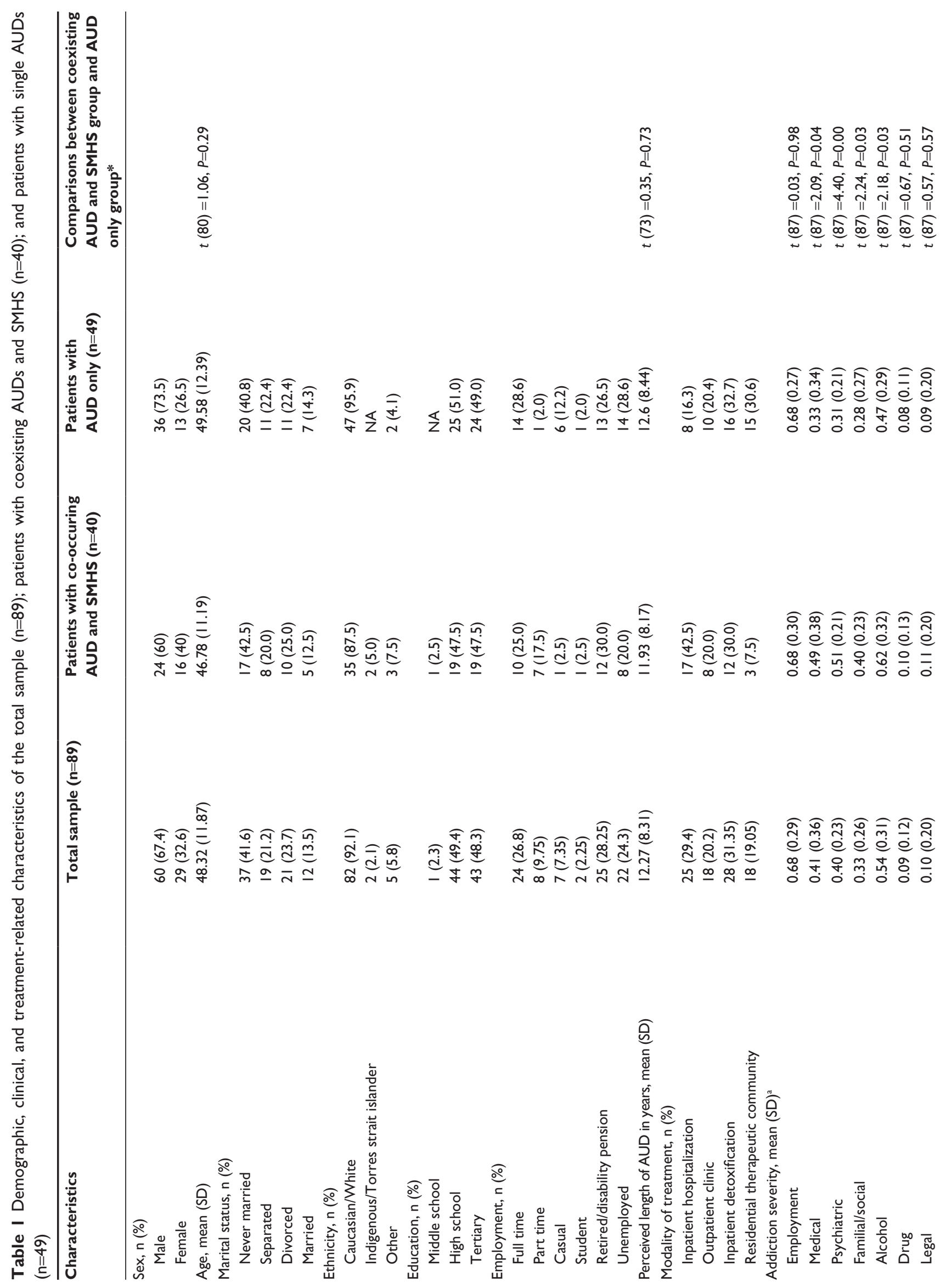




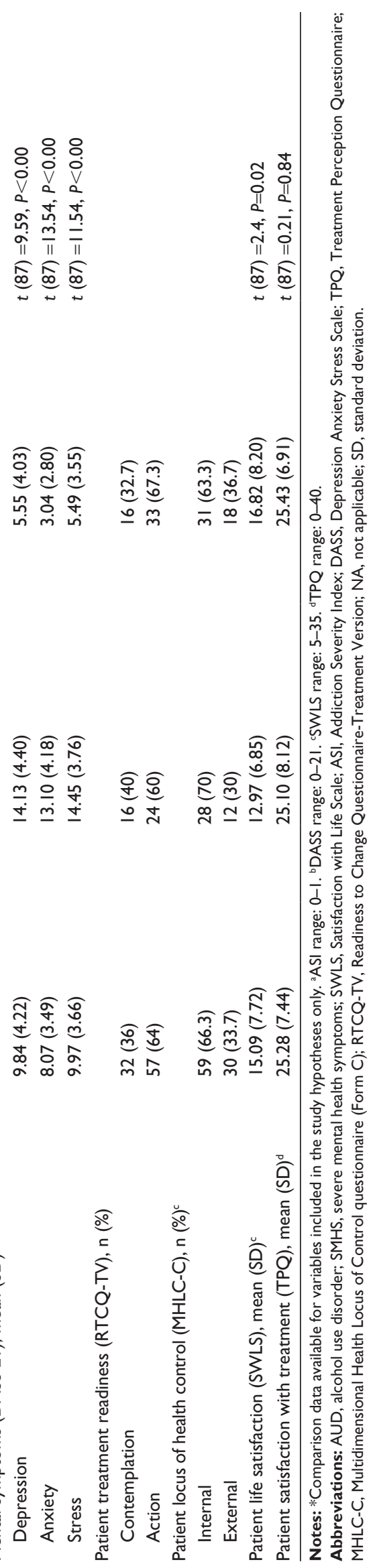

variables: treatment modality, treatment readiness, health locus of control, and satisfaction with life. Confounding variables explained only $12.8 \%$ of the total variance in patient satisfaction with treatment. After entry of patient mental symptoms, the total variance explained by the model was $12.9 \%$ and was not significant $(P=0.75)$. Patient mental symptoms explained only $0.1 \%$ of the variance in patient satisfaction, after accounting for the confounding variables $(P=0.75)$. In the final model, only the inpatient hospitalization variable remained statistically significant $(P=0.03)$. Receiving treatment as an inpatient in hospital, as opposed to the outpatient or residential/therapeutic community setting, was associated with a 4.45-point decrease on the measure of patient satisfaction with treatment.

\section{Comparing satisfaction with treatment among patients with and without SMHS}

Patients with SMHS were significantly more likely to "strongly disagree" with the statement "the staff have understood the kind of help I want" compared to patients without SMHS ( $P=0.02$; Table 3$)$. No other differences were observed between the two groups. Twenty percent of patients with SMHS were dissatisfied with treatment rules and regulations; however, this was not statistically different to patients with an AUD alone (12.2\%). Similarly, patients with SMHS were more dissatisfied with the statement "staff and I have similar ideas about what my treatment objectives should be" ( $7.5 \%$ vs $0 \%)$; however, this was not statistically significant between the groups.

\section{Open-ended responses about improvements to services}

Of the 89 completed surveys, 51 (57\%) included a response to the open-ended question about how services might be improved to better accommodate patient needs. As quantitative data indicated little differences between groups, we explored results of the open-ended survey question across the total sample. Twenty-one (41\%) of the responses were positive appraisals of staff and treatment. Thirty responses (59\%) were comments relating to patient dissatisfaction or areas for improvement. Content analysis of the responses provided by patients detected five areas of treatment that patients believed could be improved.

\section{Staff qualities}

Patients explained that it was important for all service staff to be sufficiently trained in addiction, to understand the nature of their condition and provide best treatment practice: 
Table 2 Impact of mental health symptoms on patient satisfaction with treatment, while accounting for the impact of treatment setting, treatment readiness, locus of health control, and satisfaction with life

\begin{tabular}{|c|c|c|c|c|c|c|c|}
\hline Predictor & B & SE B & $\beta$ & $t$ & $P$-value & $R^{2}$ & $R^{2}$ change \\
\hline \multicolumn{8}{|l|}{ Model I } \\
\hline \multicolumn{8}{|l|}{ Step I } \\
\hline Inpatient hospitalization* & -4.45 & 2.06 & -0.27 & -2.16 & 0.03 & & \\
\hline Outpatient & -2.68 & 2.33 & -0.15 & -1.16 & 0.25 & & \\
\hline Residential therapeutic community & -4.29 & 2.46 & -0.23 & -1.74 & 0.08 & & \\
\hline Treatment readiness & 2.23 & 1.80 & 0.15 & 1.24 & 0.22 & 0.128 & \\
\hline Health locus of control & -1.64 & 1.66 & -0.11 & -0.99 & 0.33 & & \\
\hline Satisfaction with life & 0.17 & 0.12 & 0.18 & 1.44 & 0.15 & & \\
\hline \multicolumn{8}{|l|}{ Step 2} \\
\hline Mental symptoms & 0.55 & 1.73 & 0.04 & 0.31 & 0.75 & 0.129 & $0.00 I^{\ddagger}$ \\
\hline \multicolumn{8}{|l|}{ Model 2} \\
\hline \multicolumn{8}{|l|}{ Step I } \\
\hline Inpatient hospitalization & -0.16 & 2.66 & -0.01 & -0.06 & 0.95 & & \\
\hline Outpatient clinic & 1.61 & 2.84 & 0.09 & 0.57 & 0.57 & & \\
\hline Inpatient detoxification & 4.29 & 2.46 & 0.27 & 1.74 & 0.09 & & \\
\hline Treatment readiness & 2.23 & 1.80 & 0.15 & 1.24 & 0.22 & & \\
\hline Health locus of control & -1.64 & 1.66 & -0.11 & -0.99 & 0.33 & 0.128 & \\
\hline Satisfaction with life & 0.17 & 0.12 & 0.18 & 1.44 & 0.15 & & \\
\hline \multicolumn{8}{|l|}{ Step 2} \\
\hline Mental health symptoms & 0.55 & 0.73 & 0.04 & 0.31 & 0.75 & 0.129 & $0.00 I^{\ddagger}$ \\
\hline
\end{tabular}

Notes: Unstandardized regression coefficients $(B)$, unstandardized regression coefficients standard error $(\mathrm{SE} B)$, standardized regression coefficients $(\beta), t$-values $(t), P$-values $(P)$, $R$ square values $\left(R^{2}\right)$, and $R$ square change $\left(R^{2}\right.$ change), $* P<0.05 ; F F(7.81)=1.71, P>0.05, R^{2}$ change $=0.001, F$ change $(I .81)=0.099$. Values in bold indicate statistically significant data.

Staff need to be more sympathetic and listen carefully to the mental states of patients. There is no one formula to fix every patient in the same way, there is no average alcoholic. [25 year old male with SMHS; inpatient detoxification service].

\section{Keeping the patient informed}

Patients expressed a desire to be better informed about what to expect during treatment. Patients wished to be regularly informed of the medications they were given, reasoning for changing doses, results of monitoring, ie, blood pressure, and better explanation of what happens to the body through withdrawal.

\section{Treatment access and continuity}

Many patients described difficulties with accessing treatment, including lack of treatment services available, long waiting periods for services, and the cost of medications. Patients also described dissatisfaction with the coordination between services and were concerned about what treatment resources were available postdischarge.

Table 3 Percentage of patients in the sample who responded strongly disagree to each item of the Treatment Perception Questionnaire (TPQ)

\begin{tabular}{lll}
\hline TPQ item & $\begin{array}{l}\text { Patients with coexisting } \\
\text { AUD and SMHS (n=40) }\end{array}$ & $\begin{array}{l}\text { Patients with AUD } \\
\text { only (n=49) }\end{array}$ \\
\hline (a) The staff have understood the kind of help I want* & $17.5 \% *$ & $2.0 \% *$ \\
(b) I have been well informed about decisions made about my treatment & $5.0 \%$ & $4.1 \%$ \\
(c) The staff and I have had similar ideas about what my treatment objectives should be & $7.5 \%$ & $0.0 \%$ \\
(d) There has always been a member of staff available when I have wanted to talk & $10.0 \%$ & $10.2 \%$ \\
(e) The staff have helped to motivate me to sort out my problems & $10.0 \%$ & $8.2 \%$ \\
(f) I have liked the treatment sessions I have attended & $7.5 \%$ & $4.1 \%$ \\
(g) I have had enough time to sort out my problems & $10.0 \%$ & $4.1 \%$ \\
(h) I think the staff have been good at their jobs & $2.5 \%$ & $8.2 \%$ \\
(i) I have received the help that I was looking for & $5.0 \%$ & $10.2 \%$ \\
(j) I have liked most of the treatment rules or regulations & $20.0 \%$ & $12.2 \%$ \\
\hline
\end{tabular}

Notes: $* P<0.05$. Table adapted from Marsden J, Stewart D, Gossop M, et al. Assessing Client Satisfaction with Treatment for Substance Use Problems and the Development of the Treatment Perceptions Questionnaire (TPQ). Addiction Research. 2000;8(5):455-470. Reprinted by permission of the publisher (Taylor \& Francis Ltd, www.tandfonline.com). ${ }^{3}$

Abbreviations: AUD, alcohol use disorder; SMHS, severe mental health symptoms. 


\section{Issues relating to inpatient stay}

Patient dissatisfaction with treatment was often related to issues of inpatient stay. Issues included being bored, a lack of privacy with shared rooms, feeling scared, and personality clashes with other inpatients. Patients in the inpatient detoxification service suggested that outdoor program activities would reduce their stress in treatment, eg, vegetable garden, animal visits, outdoor painting, outdoor exercise, and smoking areas.

\section{Mental health treatment needs}

Patients expressed a desire for treatment to focus more on their mental health symptoms. Patients suggested assessments of mental health, improved mental treatment plans, and increased one-on-one access to a full-time drug and alcohol counselor:

Some counseling and mental treatment plans need to be more systematic in their approach, at times I have felt mismanaged or unmanaged, no overarching plan in existence. [37 year old male with SMHS; inpatient detoxification service].

\section{Discussion}

Studies to date have yet to control for potential confounding variables that have been linked to patient satisfaction for single diagnosis samples. ${ }^{4}$ Thus, this is the first study to account for the impact of treatment setting, treatment readiness, locus of health control, and life satisfaction, when comparing patient satisfaction with standard AUD treatment, among patients with and without SMHS. This study was strengthened by specific assessment of the most common symptoms of mental illness in AUD patient groups, at the time of treatment. Other strengths of this study include the incorporation of various treatment settings and comprehensive assessment of patient mental symptoms. Previous studies report that SMHS often go undetected and untreated in addiction treatment settings, despite widespread recognition of the negative impact they have on patient outcomes. ${ }^{13,19}$

Results suggest that patients in this sample were, on average, satisfied with the treatment they received. In fact, patients with SMHS reported higher treatment satisfaction scores than treatment samples with co-occurring diagnoses in the UK, ${ }^{48-50}$ according to the same satisfaction measure. Similarly, the single AUD patient group reported higher satisfaction scores than single substance use disorder treatment samples in Scotland, ${ }^{23}$ Spain, ${ }^{51}$ and inpatients in England; ${ }^{52}$ comparable satisfaction scores to patients in Italy; ${ }^{51}$ and reduced satisfaction compared to patients in Portugal ${ }^{51}$ and outpatients in England, ${ }^{52}$ using the same satisfaction measure. However, the diagnostic characteristics of the samples included in these studies were dissimilar to the current study, limiting meaningful cross-comparison of satisfaction data. Contrary to our predictions, results indicate that patients with SMHS were equally satisfied with treatment as patients with single AUD, even after accounting for confounding variables. This result supports previous findings reported by two small-scale studies ${ }^{11,22}$ and adds further evidence that standard treatment may indeed address the needs of patients with SMHS. ${ }^{4}$ Results also suggest that factors such as treatment readiness, health locus of control, and satisfaction with life had minimal impact on satisfaction with treatment for patients in this sample. It is often thought that patients who report negative experiences of treatment are likely to lack motivation, ${ }^{4}$ lack a personal responsibility for change, ${ }^{24,25}$ or might be inclined to negatively appraise experiences; ${ }^{26}$ however, the results obtained from this study do not support this. The only variable to significantly impact on patient satisfaction with treatment was inpatient hospitalization. This result might suggest that patient needs may be better addressed in other settings and supports results from a similar study that found that inpatients were significantly less satisfied with opioid substitution treatment when compared to outpatients in the same treatment program. ${ }^{52}$ At the same time however, it is probable that inpatients are likely to report poorer experiences of treatment due to their more immediate and severe needs, rather than the setting itself. In fact, patients in the hospital in this study were more likely to report SMHS compared to other settings, with SMHS being associated with higher medical, familial/social, and alcohol severity.

On the whole, quantitative analyses revealed minimal differences between the groups in respect to patient satisfaction with treatment. However, a major finding was that patients with SMHS were more dissatisfied with staff understanding of the type of help they wanted in treatment (17.5\% vs $2 \%$ ). The importance patients place on their relationship with staff is well documented in the literature, ${ }^{53,54}$ particularly staff skills in empathizing with patient needs. ${ }^{55,56}$ This was reflected by the qualitative content analysis findings, where patients indicated staff qualities as an area for improvement. In addition, quantitative findings might suggest that patients with co-occurring SMHS want existing treatments to recognize their psychological symptoms and accommodate suitable interventions to address symptoms. Although differences were statistically nonsignificant, patients with SMHS were more dissatisfied with the statement "staff and I have 
similar ideas about what my treatment objectives should be" (7.5\% vs $0 \%)$ and "I have liked most of the treatment rules and regulations" (20\% vs $12.2 \%$ ) than those without SMHS. This may reflect the qualitative findings, where patients with SMHS discussed their desire for treatment to address their mental health symptom needs. Patients also indicated that improvements could be achieved by managing patient expectations through informative communication, improving treatment access and patient linkage through services, addressing issues of inpatient stay, and placing more emphasis on patients' mental symptoms.

This study contained several limitations. First, patient satisfaction with treatment was assessed at one time point, and time-in-treatment was also not controlled for. Satisfaction is recognized as a dynamic construct and it is likely that patients' satisfaction would have changed throughout treatment. ${ }^{57}$ Patients were required to attend their outpatient appointment or be engaged in treatment for at least 5 days, consequently $15 \%$ of patients meeting inclusion criteria were not approached for participation. It is likely that patients who did not attend their appointment or who prematurely discharged themselves from treatment might have been dissatisfied. Therefore, this study's sample may have contained a higher concentration of satisfied patients and may not be a true representation of the views of all patients in treatment. Future studies should aim to assess satisfaction throughout treatment and attempt to track and assess the views of patients who do not attend or prematurely discharge themselves from treatment. Another limitation of this study was that patient groups were stratified according to symptoms of mental illness, rather than standardized diagnostic assessments. Similarly, it is likely that the validity of the TPQ measure was reduced in the $\chi^{2}$ data analyses, as responses were recoded from continuous to dichotomous responses. There exists some research indicating the limitedness of the Mini Mental State Examination in detecting cognitive impairment for patients with AUD, due to the absence of its ceiling effects and items assessing executive functioning, which are areas commonly affected by alcohol. ${ }^{58}$ However, one study suggests the Mini Mental State Examination is a suitable screening tool for research containing patients with AUDs, ${ }^{34}$ and it is routinely employed in current clinical practice. Finally, this study only assessed patients' explicit attitudes through self-reported assessment of patients' perceptions of treatment. Studies argue that measures of automatic, implicit attitudes provide superior predictive power in comparison to measures of explicit attitudes. ${ }^{59}$ It is possible that including measures of implicit attitudes in this study may have yielded different results.
This study's findings have important implications for health care delivery and health care decision making with regard to improving treatment for patients with SMHS, based on the patients' perception of care. First, findings present a positive result for local AUD services and should instill confidence in clinicians' abilities to address the needs of patients both with and without SMHS. To improve the patient experiences of treatment, staff should feel confident in their ability to listen, understand, and respond to the type of help patients want and need in treatment. To improve patient experiences of treatment, service directors and policy makers are encouraged to consider the areas nominated by patients for review. Patients indicated that gains could be made by recognizing the importance of staff selection and training, more active management of patient expectations, handling confrontations among inpatients, and acknowledging patient mental symptoms. Similarly, service directors are encouraged to focus on improving the activities and opportunities available to inpatients in detox and address any issues patients might be experiencing in accessing and linking to services.

\section{Conclusion}

The complex needs of patients with coexisting AUDs and SMHS are often not fully addressed by standard AUD treatment, and thus might explain patients' poorer treatment outcomes when compared to single AUD patients. However, this study found that patients with SMHS reported comparable experiences of standard treatment to patients with AUDs alone, suggesting that their complex needs were adequately met during treatment. Further research is, therefore, required to better understand ways to improve outcomes for patients with coexisting mental health and alcohol-related symptoms after treatment.

\section{Acknowledgments}

The authors thank all participants who volunteered their time to partake in the study. They also thank all treatment staff and Drug and Alcohol Services South Australia for their efforts in patient recruitment.

\section{Disclosure}

The authors report no conflicts of interest in this work.

\section{References}

1. Teesson M, Hall W, Lynskey M, Degenhardt L. Alcohol and drug use disorders in Australia: implications of the National Survey of Mental Health and Wellbeing. Aust N Z J Psychiatry. 2000;34:206-213.

2. Substance Abuse and Mental Health Services Administration. Discharges from Substance Abuse Treatment Services, DASIS Series. Rockville, MD: SAMHSA; 2008. 
3. Marsden J, Stewart D, Gossop M, et al. Assessing client satisfaction with treatment for substance use problems and the development of the treatment perceptions questionnaire (TPQ). Addict Res Theory. 2000; $8(5): 455-470$.

4. Schulte SJ, Meier PS, Stirling J. Dual diagnosis clients' treatment satisfaction: a systematic review. BMC Psychiatry. 2011;11:64-76.

5. Dearing RL, Barrick C, Dermen KH, Walitzer KS. Indicators of client engagement: influences on alcohol treatment satisfaction and outcomes. Psychol Addict Behav. 2005;19(1):71.

6. Rosenheck R, Wilson NJ, Meterko M. Influence of patient and hospital factors on consumer satisfaction with inpatient mental health treatment. Psychiatr Serv. 1997;48(12):1553-1561.

7. Sanders LM. Assessment of client satisfaction in a peer counseling substance abuse treatment program for pregnant and postpartum women. Eval Program Plann. 1998;21(3):287-296.

8. Hiller ML, Knight K, Simpson DD. Prison based substance abuse treatment, residential aftercare and recidivism. Addiction. 1999;94(6):833-842.

9. Kasprow WJ, Frisman L, Rosenheck RA. Homeless veterans' satisfaction with residential treatment. Psychiatr Serv. 1999;50(4):540-545.

10. Grant BF, Stinson FS, Dawson DA, et al. Prevalence and co-occurrence of substance use disorders and independent mood and anxiety disorders: results from the national epidemiologic survey on alcohol and related conditions. Arch Gen Psychiatry. 2004;61:807-816.

11. Burns L, Teesson M, O'Neill K. The impact of comorbid anxiety and depression on alcohol treatment outcomes. Addiction. 2005;100: 787-796.

12. Mills KL, Deady M, Proudfoot H, et al. Guidelines on the Management of Co-occurring Alcohol and Other Drug and Mental Health Conditions in Alcohol and Other Drug Treatment Settings. Sydney, Australia: National Drug and Alcohol Research Centre; 2010.

13. Kay-Lambkin FJ, Baker AL, Lewin TJ. The "co-morbidity roundabout": a framework to guide assessment and intervention strategies and engineer change among people with co-morbid problems. Drug Alcohol Rev. 2004;23:407-423.

14. Boden MT, Moos R. Dually diagnosed patients' responses to substance use disorder treatment. J Subst Abuse Treat. 2009;37:335-345.

15. Burns L, Teesson M. Alcohol use disorders comorbid with anxiety, depression and drug use disorders: findings from the Australian National Survey of Mental Health and Well Being. Drug Alcohol Depend. 2002 68:299-307.

16. Bronisch T, Wittchen HU. Suicidal ideation and suicide attempts: comorbidity with depression, anxiety disorders, and substance abuse disorder. Eur Arch Psychiatry Clin Neurosci. 1994;244:93-98.

17. Helzer JE, Pryzbeck TR. The co-occurrence of alcoholism with other psychiatric disorders in the general population and its impact on treatment. J Stud Alcohol Drugs. 1988;49:219.

18. Wu LT, Kouzis AC, Leaf PJ. Influence of comorbid alcohol and psychiatric disorders on utilization of mental health services in the National Comorbidity Survey. Am J Psychiatry. 1999;156:1230-1236.

19. Saunders B, Robinson S. Co-occurring mental health and drug dependency disorders: work-force development challenges for the AOD field. Drug Alcohol Rev. 2002;21:231-237.

20. Fein G, Di Sclafani V, Finn P, Scheiner DL. Sub-diagnostic psychiatric comorbidity in alcoholics. Drug Alcohol Depend. 2007;87:139-145.

21. Driessen M, Meier S, Hill A, Wetterling T, Lange W, Junghanns K. The course of anxiety, depression and drinking behaviours after completed detoxification in alcoholics with and without comorbid anxiety and depressive disorders. Alcohol Alcohol. 2001;36:249-255.

22. Herrell JM, Fenton W, Mosher LR, Hedlund S, Lee B. Residential alternatives to hospitalization for patients with severe and persistent mental illness: should patients with comorbid substance abuse be excluded? J Ment Health Adm. 1996;23:348-355.

23. Morris ZS, McKeganey N. Client perceptions of drug treatment services in Scotland. Drugs. 2007;14:49-60.

24. Donovan DM, Rohsenow DJ, Schau EJ, O’Leary MR. Defensive style in alcoholics and nonalcoholics. J Stud Alcohol Drugs. 1977; $38: 465$.
25. Miller WR. Motivation for treatment: a review with special emphasis on alcoholism. Psychol Bull. 1985;98:84.

26. Diener E, Emmons RA, Larsen RJ, Griffin S. The satisfaction with life scale. J Pers Assess. 1985;49(1):71-75.

27. Lecrubier Y, Sheehan D, Weiller E, et al. The Mini International Neuropsychiatric Interview (MINI). A short diagnostic structured interview: reliability and validity according to the CIDI. Eur Psychiatry. 1997;12(5):224-231.

28. Mewton L, Slade T, McBride O, Grove R, Teesson M. An evaluation of the proposed DSM 5 alcohol use disorder criteria using Australian national data. Addiction. 2011;106(5):941-950.

29. Folstein S, McHugh P. "Mini-Mental State": a practical method for grading the cognitive state of patients for the clinician. J Psychiatr Res. 1975;12:189-198.

30. Rosen CS, Henson BR, Finney JW, Moos RH. Consistency of self administered and interview based Addiction Severity Index composite scores. Addiction. 2000;95(3):419-425.

31. McLellan AT, Kushner H, Metzger D, et al. The fifth edition of the addiction severity index. J Subst Abuse Treat. 1992;9(3):199-213.

32. McLellan AT, Luborsky L, Woody GE, O’Brien CP. An improved diagnostic evaluation instrument for substance abuse patients: the addiction severity index. J Nerv Ment Dis. 1980;168(1):26-33.

33. Rush JR, First MB, Blacker D. Handbook of Psychiatric Measures. 2nd ed. Arlington, VA: American Psychiatric Publishing; 2008.

34. O'Cathain A, Murphy E, Nicholl J. Why, and how, mixed methods research is undertaken in health services research in England: a mixed methods study. BMC Health Serv Res. 2007;7(1):85.

35. Heather N, Luce A, Peck D, Dunbar B, James I. Development of a treatment version of the readiness to change questionnaire. Addict Res Theory. 1999;7(1):63-83.

36. Rollnick S, Heather N, Gold R, Hall W. Development of a short "readiness to change"questionnaire for use in brief, opportunistic interventions among excessive drinkers. Br J Addict. 1992;87(5):743-754.

37. Prochaska JO, DiClemente CC. Stages of change in the modification of problem behaviors. Prog Behav Modif. 1991;28:183-218.

38. Wallston KA. The validity of the multidimensional health locus of control scales. J Health Psychol. 2005;10(5):623-631.

39. Wallston KA, Wallston BS, DeVellis R. Development of the multidimensional health locus of control (MHLC) scales. Health Educ Behav. 1978;6(1):160-170.

40. Wallston KA, Stein MJ, Smith CA. Form C of the MHLC scales: a condition-specific measure of locus of control. J Pers Assess. 1994;63: 534-553.

41. Pavot W, Diener E, Colvin CR, Sandvik E. Further validation of the satisfaction with life scale: evidence for the cross-method convergence of well-being measures. J Pers Assess. 1991;57:149-161.

42. Lovibond PF, Lovibond SH. The structure of negative emotional states: comparison of the depression anxiety stress scales (DASS) with the beck depression and anxiety inventories. Behav Res Ther. 1995;33(3): 335-343.

43. Fischer J, Corcoran K. Measures for Clinical Practice and Research: A Sourcebook. Vol. 2. 4th ed. New York, NY: Oxford University Press; 2007.

44. Peduzzi P, Concato J, Kemper E, Holford TR, Feinstein AR. A simulation study of the number of events per variable in logistic regression analysis. J Clin Epidemiol. 1996;49(12):1373-1379.

45. Krippendorff K. Content Analysis: An Introduction to its Methodology. London, UK: SAGE; 2012.

46. Weber RP. Basic Content Analysis. London, UK: SAGE; 1990.

47. Elo S, Kyngas $\mathrm{H}$. The qualitative content analysis process. J Adv Nurs. 2008;62(1):107-115.

48. Afuwape SA, Johnson S, Craig TJ, et al. Ethnic differences among a community cohort of individuals with dual diagnosis in South London. J Ment Health. 2006;15(5):551-567.

49. Miles H, Johnson S, Amponsah-Afuwape S, Finch E, Leese M, Thornicroft G. Characteristics of subgroups of individuals with psychotic illness and a comorbid substance use disorder. Psychiatr Serv. 2003;54(4):554-561. 
50. Craig T, Johnson S, McCrone $\mathrm{P}$, et al. Integrated care for co-occurring disorders: psychiatric symptoms, social functioning, and service costs at 18 months. Psychiatr Serv. 2008;59(3):276-282.

51. Marsden J, Nizzoli U, Corbelli C, et al. New European instruments for treatment outcome research: reliability of the maudsley addiction profile and treatment perceptions questionnaire in Italy, Spain and Portugal. Eur Addict Res. 2000;6(3):115-122.

52. Day E, Strang J. Outpatient versus inpatient opioid detoxification: a randomized controlled trial. J Subst Abuse Treat. 2011;40(1):56-66.

53. Ball SA, Carroll KM, Canning-Ball M, Rounsaville BJ. Reasons for dropout from drug abuse treatment: symptoms, personality, and motivation. Addict Behav. 2006;31(2):320-330.

54. Madden A, Lea T, Bath N, Winstock A. Satisfaction guaranteed? What clients on methadone and buprenorphine think about their treatment. Drug Alcohol Rev. 2008;27(6):671-678.
55. Miller WR. Motivational Enhancement Therapy Manual: A Clinical Research Guide for Therapists Treating Individuals with Alcohol Abuse and Dependence. Vol. 2. Collingdale, PA: DIANE Publishing; 1994.

56. Monti PM. Treating Alcohol Dependence: A Coping Skills Training Guide. New York, NY: Guilford Press; 2002.

57. Rejas J, Ruiz M, Pardo A, Soto J. Detecting changes in patient treatment satisfaction with medicines: the SATMED-Q. Value Health. 2013; 16:88-96.

58. Juby A, Tench S, Baker V. The value of clock drawing in identifying executive cognitive dysfunction in people with a normal Mini-Mental State Examination score. CMAJ. 2002;167(8):859-864.

59. Houben R, Gijsen A, Peterson J, De Jong P, Vlaeyen J. Do health care providers' attitudes towards back pain predict their treatment recommendations? Differential predictive validity of implicit and explicit attitude measures. Pain. 2005;114(3):491-498.

\section{Publish your work in this journal}

Patient Preference and Adherence is an international, peer-reviewed, open access journal that focuses on the growing importance of patient preference and adherence throughout the therapeutic continuum. Patient satisfaction, acceptability, quality of life, compliance, persistence and their role in developing new therapeutic modalities and compounds to optimize clinical outcomes for existing disease states are major areas of interest for the journal. This journal has been accepted for indexing on PubMed Central. The manuscript management system is completely online and includes a very quick and fair peer-review system, which is all easy to use. Visit http://www dovepress.com/testimonials.php to read real quotes from published authors.

Submit your manuscript here: http://www.dovepress.com/patient-preference-and-adherence-journal 